\title{
Sex disparities in COVID-19 outcomes of inpatients with diabetes: insights from the CORONADO study
}

Blandine Tramunt ${ }^{1 *}$, Sarra Smati2*, Sandrine Coudol $^{3}$, Matthieu Wargny ${ }^{2,3}$, Matthieu Pichelin ${ }^{2}$, Béatrice Guyomarch ${ }^{4}$, Abdallah Al-Salameh ${ }^{5}$, Coralie Amadou ${ }^{6}$, Sara Barraud ${ }^{7,8}$, Edith Bigot ${ }^{9}$, Lyse Bordier ${ }^{10}$, Sophie Borot ${ }^{11}$, Muriel Bourgeon ${ }^{12}$, Olivier Bourron ${ }^{13}$, Sybil Charrière $^{14}$, Nicolas Chevalier ${ }^{15}$, Emmanuel Cosson ${ }^{16,17}$, Bruno Fève ${ }^{18,19}$, Anna FlausFurmaniuk $^{20}$, Pierre Fontaine ${ }^{21}$, Amandine Galioot ${ }^{22}$, Céline Gonfroy-Leymarie ${ }^{23}$, Bruno Guerci $^{24}$, Sandrine Lablanche ${ }^{25}$, Jean-Daniel Lalau ${ }^{5}$, Etienne Larger ${ }^{26}$, Adèle Lasbleiz ${ }^{27}$, Bruno Laviolle ${ }^{28}$, Michel Marre ${ }^{29}$, Marion Munch ${ }^{30}$, Louis Potier $^{31,32}$, Gaëtan Prevost ${ }^{33}$, Eric Renard $^{34}$, Yves Reznik ${ }^{35}$, Dominique Seret-Bégué ${ }^{36}$, Paul Sibilia ${ }^{37}$, Philippe Thuillier ${ }^{38}$, Bruno Vergès $^{39}$, Jean-François Gautier ${ }^{40,41}$, Samy Hadjadj², Bertrand Cariou ${ }^{2}$, Franck MauvaisJarvis $^{42,43,44 *}$, Pierre Gourdy ${ }^{1 *}$ for the CORONADO investigators.

${ }^{1}$ Department of Diabetology, Metabolic Diseases \& Nutrition, Toulouse University Hospital, Institute of Metabolic \& Cardiovascular Diseases, UMR1297 INSERM/UPS, Toulouse University, Toulouse, France

2 Nantes University, Nantes University Hospital, CNRS, INSERM, L'institut du thorax, Nantes, France.

${ }^{3}$ CIC-EC 1413, Data Clinic, Nantes University Hospital, Nantes, France.

${ }^{4}$ Research Department, Methodology and Biostatistics Platform, Nantes University Hospital, Nantes, France.

${ }^{5}$ Department of Endocrinology, Diabetes Mellitus and Nutrition, Amiens University Hospital, 80054 Amiens, France; PériTox=UMR_I 01, University of Picardie Jules Verne, Amiens, France. 
${ }^{6}$ Department of Diabetology, Sud Francilien Hospital Center, Corbeil Essonne, France.

${ }^{7}$ CRESTIC EA 3804, University of Reims Champagne Ardenne, UFR Sciences Exactes et Naturelles, Moulin de la Housse, Reims, France.

${ }^{8}$ Reims University Hospital, Department of Endocrinology-Diabetes-Nutrition, Avenue du Général Koenig, Reims, France

${ }^{9}$ Department of Biochemistry, Nantes University Hospital, G et R Laënnec Hospital, Bd Jacques Monod, Nantes, France

${ }^{10}$ Department of Endocrinology, Bégin Hospital, Saint-Mandé, France.

${ }^{11}$ Department of Endocrinology, Diabetology and Nutrition, Besançon University Hospital, Besançon, France.

${ }^{12}$ Department of Endocrinology, Diabetology and Nutrition, Assistance Publique Hôpitaux de Paris, Paris Saclay University, Antoine Béclère Hospital, Clamart, Bicêtre Hospital, Le Kremlin Bicêtre, France.

13 Sorbonne University, Assistance Publique Hôpitaux de Paris, Department of Diabetology, La Pitié Salpêtrière-Charles Foix University Hospital, Inserm, UMR_S 1138, Cordeliers Research Center, Paris 06, Institute of Cardiometabolism and Nutrition ICAN, Paris, France.

${ }^{14}$ Federation of Endocrinology - Louis Pradel Cardiovascular Hospital, Hospices Civils de Lyon, INSERM UMR 1060 Carmen, Claude Bernard Lyon 1 University, Lyon, France.

15 University of Côte d'Azur, University Hospital, Inserm U1065, C3M, Nice, France.

${ }^{16}$ Assistance Publique Hôpitaux de Paris, Avicenne Hospital, Paris 13 University, Sorbonne Paris Cité, Department of Endocrinology, Diabetology and Nutrition, CRNH-IdF, CINFO, Bobigny, France.

17 Paris 13 University, Sorbonne Paris Cité, UMR U557 Inserm / U11125 INRAE / CNAM / Paris13 University, Nutritional Epidemiological Research Unit, Bobigny, France. 
18 Assistance Publique Hôpitaux de Paris, Saint-Antoine Hospital, Reference Center of Rare Diseases of Insulin Secretion and Insulin Sensitivity (PRISIS), Department of Endocrinology, Paris, France.

${ }^{19}$ Sorbonne University, Inserm UMRS 938, Saint-Antoine Research Center, Paris, France.

${ }^{20}$ Department of Endocrinology-Diabetology, Felix Guyon Site, University Hospital of la Réunion, Saint-Denis de la Réunion, France.

21 Department of Endocrinology, Diabetology and Nutrition, Hospital of Huriez, Lille University Hospital, Lille, France.

${ }^{22}$ Department of Endocrinology, Diabetology and Nutrition, Bordeaux University Hospital and University of Bordeaux, France.

${ }^{23}$ Department of Endocrinology and Diabetology, Hospital of Pontoise, Pontoise, France.

${ }^{24}$ Lorraine University and Endocrinology, Diabetology, Metabolic Diseases and Nutrition, Nancy University Hospital, Nancy, France.

25 Grenoble Alpes University, INSERM U1055, LBFA, Endocrinology, Grenoble Alpes University Hospital, France.

${ }^{26}$ Department of Diabetology, Cochin Hospital, AP-HP, Paris University, Paris, France.

27 Department of Endocrinology, Diabetology and Nutrition, Hospital of la Conception, Assistance Publique-Hôpitaux de Marseille, Marseille, France - Aix Marseille University, INSERM, INRA, C2VN, Marseille, France.

${ }^{28}$ Rennes University, Rennes University Hospital, Inserm, CIC 1414 (Clinical Investigation Center), Rennes, France.

29 Ambroise Paré Neuilly-sur-Seine Hospital, Cordeliers Research Center, Paris Diderot University, Paris, France.

${ }^{30}$ Department of Endocrinology, Diabetology and Nutrition, Strasbourg University Hospitals, Strasbourg France. 
31 Department of Endocrinology, Diabetology and Nutrition, Bichat Hospital, Assistance Publique Hôpitaux de Paris, Paris, France.

${ }^{32}$ Cordeliers Research Center, Inserm, U-1138, Paris University, Paris, France.

33 Department of Endocrinology, Diabetes and Metabolic Diseases, Normandie Univ, UNIROUEN, Rouen University Hospital, Rouen, France.

34 Department of Endocrinology, Diabetes, Nutrition, Montpellier University Hospital, INSERM Clinical Investigation Centre, Institute of Functional Genomics, CNRS, INSERM, University of Montpellier, 1411, Montpellier, France.

35 Department of Endocrinology and Diabetology, University Hospital of Côte de Nacre, 14033 Caen cedex, France.

${ }^{36}$ Department of Diabetology, Hospital of Gonesse, Gonesse, France.

37 Department of Endocrinology, Diabetology and Nutrition, Angers University Hospital, Angers, France.

${ }^{38}$ Department of Endocrinology, Brest University Hospital, EA 3878 GETBO, Brest, France.

${ }^{39}$ Department of Endocrinology, Diabetology and Metabolic Diseases, Hospital of Bocage, Dijon, France.

40 Department of Diabetology and Endocrinology, Lariboisière Hospital, APHP, Paris, France.

${ }^{41}$ INSERM UMRS 1138, Paris Diderot-Paris VII University, Sorbonne Paris Cité, Paris, France.

${ }^{42}$ Section of Endocrinology, John W Deming Department of Medicine, Tulane University School of Medicine, New Orleans, LA, USA.

${ }^{43}$ Southeast Louisiana Veterans Health Care System Medical Center, New Orleans, LA, USA.

${ }^{44}$ Tulane Center of Excellence in Sex-Based Biology \& Medicine, New Orleans, LA, USA. 
A complete list of the CORONADO trial investigators is provided in a supplemental appendix.

* Drs B. Tramunt and S. Smati contributed equally to the work. Drs F. Mauvais-Jarvis and P. Gourdy contributed equally to the work.

\section{Running head (37 characters and spaces combined)}

Sex and COVID-19 outcomes in diabetes

\section{Keywords:}

Sex difference, COVID-19, Diabetes, Outcomes, Inflammation

\section{Corresponding authors}

Franck Mauvais-Jarvis, Section of Endocrinology, John W Deming Department of Medicine, Tulane University School of Medicine, New Orleans, LA, USA. Email address: fmauvais@tulane.edu

Pierre Gourdy, Department of Diabetology, Metabolic Diseases and Nutrition, CHU de Toulouse, TSA 50032, 31059 Toulouse, France. E-mail address: pierre.gourdy@inserm.fr

Word count: 3660 words

Abstract word count: 245 words

Number of references: 44

Number of Tables and Figures: 4 tables and 2 figures 
Supplemental materials: 3 tables and 2 figures 


\section{ABSTRACT}

\section{Objective:}

Male sex is a determinant of severe coronavirus disease-2019 (COVID-19). We aimed to characterize sex differences in severe outcomes in adults with diabetes hospitalized for COVID-19.

\section{Methods:}

We performed a sex-stratified analysis of clinical and biological features and outcomes (i.e. invasive mechanical ventilation [IMV], death, intensive care unit [ICU] admission and home discharge at day 7 [D7] or day 28 [D28]) in 2,380 patients with diabetes hospitalized for COVID-19 and included in the nationwide CORONADO observational study (NCT04324736).

\section{Results:}

The study population was predominantly male (63.5\%). After multiple adjustments, female sex was negatively associated with the primary outcome (IMV and/or death, OR 0.66 [0.490.88]), death (OR 0.49 [0.30-0.79]) and ICU admission (OR 0.57 [0.43-0.77]) at D7, but only with ICU admission (OR 0.58 [0.43-0.77]) at D28. Older age and a history of microvascular complications were predictors of death at D28 in both sexes, while chronic obstructive pulmonary disease (COPD) was predictive of death in women only. At admission, CRP, AST and eGFR predicted death in both sexes. Lymphocytopenia was an independent predictor of death in women only, while thrombocytopenia and elevated plasma glucose concentration were predictors of death in men only.

\section{Conclusions:}

In patients with diabetes admitted for COVID-19, female sex was associated with lower incidence of early severe outcomes, but did not influence the overall in-hospital mortality, suggesting that diabetes mitigates the female protection from COVID-19 severity. Sex- 
associated biological determinants may be useful to optimize COVID-19 prevention and management in women and men. 


\section{INTRODUCTION}

Older age and specific comorbidities, such as diabetes, have been identified as the main factors associated with severe forms of coronavirus disease-2019 (COVID-19) $(1,2)$. Male sex was also recognized as a determinant of poor prognosis, and the characterization of sex differences in COVID-19 clinical presentation and outcomes could thus provide important insights to optimize prevention and management of the disease in women and men (3).

Sex differences in the course of infectious diseases and immune responses have already been described (4). As reported in previous coronavirus outbreaks $(5,6)$, sex-stratified analyses of people affected by COVID-19 in China, Europe and the United States showed a clear male predominance in hospitalization rate, intensive care unit (ICU) admission and death, while the infection rates seem to be equal between men and women $(7,8)$. For instance, $41.9 \%$ of the 1,099 patients hospitalized for COVID-19 were women in one of the first Chinese reports (9) and similar trends were observed in different regions of the world as summarized by the Global Health 50/50 (10). Such a male predominance was also observed regarding ICU admissions and the use of invasive mechanical ventilation (IMV). Accordingly, in large series of patients admitted to ICU in Italy $(n=1,591)$ and in the UK $(n=10,917)$, men accounted for $82 \%$ and $70 \%$ of the whole populations, respectively $(11,12)$. In a case series including 463 patients hospitalized for COVID-19 in Detroit (USA), male sex was similarly associated with over two-fold increased odds of ICU admission, IMV or mortality (13). In the analysis of the OpenSAFELY platform in the UK, identifying 10,926 COVID-19-related death from primary care records of 17,278,392 adults, mortality was independently associated with male sex $(\mathrm{HR}=1.59[1.53-1.65])(14)$.

In a recent analysis of 319,349 people with diabetes from the total Scottish population, male sex was also associated with a higher risk of severe COVID-19 outcome, combining death and admission to critical care unit (15). In contrast, observations from the UK Biobank 
suggest that diabetes similarly increased the risk of COVID-19-related mortality in women and men (16). Nevertheless, to date, sex differences in COVID-19 presentation and outcomes have been scarcely investigated in patients with diabetes. In the present sex-stratified analysis, we compared the clinical and biological features and outcomes in women and men included in the CORONADO (CORONAvirus-SARS-CoV-2 and Diabetes Outcomes) study, a nationwide observational study dedicated to patients with diabetes hospitalized for COVID19. We identified sex-specific clinical and biological determinants of in-hospital COVID-19related mortality. 


\section{METHODS}

\section{Study Design and Population}

The French multicenter nationwide CORONADO study (ClinicalTrials.gov NCT04324736) is a retrospective and prospective study designed to describe the phenotypic characteristics and outcomes of patients with diabetes admitted to hospital for COVID-19 between March 10 and April 10, 2020. The study was conducted in accordance with the declaration of Helsinki and French legislation, and obtained approvals from the local ethics committee (IRB/IEC GNEDS; Ref.CORONADOV2), the CEREES ( ${ }^{\circ}$ INDS:1544730) and the CNIL (DR-2020155/920129).

Full study details have been reported previously (17). Inclusion criteria were (i) hospitalization in a dedicated COVID-19 unit for biologically- (SARS-CoV-2 PCR) and/or clinically/radiologically-attested COVID-19, i.e. ground-glass opacity and/or crazy paving on chest CT scan; (ii) personal history of diabetes or newly-diagnosed diabetes on admission (i.e. $\mathrm{HbA}_{1 \mathrm{c}} \geq 6.5 \%$ during the 7 days following the hospitalization).

Participants with available data for sex, age, body mass index (BMI) and main outcomes were considered for analysis. Focusing on the relationship between sex and COVID-19 outcomes, the present analysis excluded patients receiving treatment interfering with sex hormone metabolism or action and patients without information on their routine treatment (see Flow chart, Supplemental Fig. 1).

This article follows the Strengthening the Reporting of Observational Studies in Epidemiology (STROBE) reporting guidelines for cohort studies.

\section{Data collection}

The procedure and details of data collection have been previously described (17). Briefly, classification and duration of diabetes, body weight and height (and/or BMI value) were 
collected as noted in the medical file by the physician in charge of the patient. $\mathrm{HbA}_{1 \mathrm{c}}$ considered in the analysis was determined locally in the 7 days following admission or, if not available, was the result of the last routine determination in the previous 6 months. Diabetic microvascular and macrovascular complications, as well as comorbidities and routine treatment, were noted as reported in the medical file. Whenever needed, clinical research associates and/or physicians of participating centers were asked to contact the patient's general and/or specialist practitioners, regular pharmacist and/or biomedical laboratory to complete the data collection. Moreover, COVID-19-related clinical, radiological and biological characteristics were collected on admission as well as the clinical evolution during hospital stays.

\section{Outcomes}

The pre-specified primary composite endpoint combined IMV and/or death at day 7 (D7). Patients discharged before D7 were systematically contacted on D7 to check for the nonoccurrence of these events. Pre-specified secondary outcomes included death, IMV, ICU admission and hospital discharge, all considered at D7 and day 28 (D28) for all patients alive and not discharged at D7.

\section{Statistical Analysis}

In this post-hoc analysis, the CORONADO study population was described according to the sex of the participants. Quantitative variables were expressed as mean \pm standard deviation (SD) or median $\left[25^{\text {th }}-75^{\text {th }}\right.$ percentile $]$, and categorical variables as no. (\%) of patients. Logistic regressions were conducted to test the association of each variable with sex, without adjustment and adjusted for age. In these models, natural-log transformation was systematically considered to better fulfil the linearity assumption, and finally applied to BMI, 
diabetes duration and biological variables. The quantitative variables were also standardized. The same approach was also performed to study the association with the different outcomes at D7 and D28, separately in men and women. Multiple logistic regression analyses were performed by sex. Models were adjusted for age, BMI, smoking, hypertension, microvascular complications, macrovascular complications, chronic obstructive pulmonary disease (COPD) and treated obstructive sleep apnea (OSA). Finally, a sensitivity analysis of sex-associated predictive factors of COVID-19-related death at D28 was performed. Four therapeutic classes have been introduced into this exploratory model, in addition to the variables selected in the previous models: metformin, insulin, DDP4-inhibitors and statins.

All statistical tests were two-sided with a type 1 error set at 5\%. All analyses were performed on available data, without imputation, using statistical software R version 4.0.3 (https://cran.rproject.org). 


\section{RESULTS}

\section{Sex-associated characteristics of patients prior to admission}

The present analysis included 2,380 patients with diabetes and confirmed diagnosis of COVID-19 admitted in 68 French hospitals between March 10 and April 10, 2020. Of note, 88 patients were excluded due to routine treatments interfering with sex hormone metabolism or action (see Flow chart, Supplemental Fig.1). A male predominance was observed in the population which included 1,512 men (63.5\%) and 868 women (36.5\%). Their clinical characteristics before admission (i.e. medical history and routine treatment) are detailed in Table 1 and Supplemental Table 1. Women were older than men (median age of 71 [61-81] vs 69 [60-78] years), with almost one third of them aged 80 years or more. Women were also characterized by a higher median BMI $\left(29.8[25.7-34.5]\right.$ vs $\left.27.8[24.9-31.2] \mathrm{kg} / \mathrm{m}^{2}\right)$ and a higher prevalence of obesity (49.2 vs 33.2\%) than men. Type 2 diabetes (T2D) was the most common type of diabetes in both sexes $(87.3 \%$ in women and $87.8 \%$ in men) and no difference was observed between women and men in terms of diabetes duration or $\mathrm{HbA}_{1 \mathrm{c}}$ level. Current or former smokers were more frequently men $(53.8 \%)$ than women $(13.8 \%)$. Macrovascular complications were less frequent in women (31.3 vs $43.0 \%)$ than in men, while the prevalence of microvascular complications was similar in both sexes. More details on diabetes complications are provided in Supplemental Table 1. Dyslipidemia and COPD were also more prevalent in men than in women but no sex difference was observed for hypertension, heart failure and OSA (Table 1). Considering medications before admission, men were more frequently treated with metformin, diuretics, antiplatelet agents and statins than women, while no difference was observed with other glucose-lowering or cardiovascular drugs (Supplemental Table 1).

\section{Sex differences in COVID-19 features at admission}


Clinical symptoms as well as radiological and biological findings at admission are detailed in Table 2. Almost all patients were symptomatic without any influence of sex on the median duration of symptoms (5 [2-9] days). Men had fever more frequently than women (77.9 vs $72.4 \%$ ), while women exhibited digestive symptoms more frequently than men (39.3\% vs $32.0 \%$, even after age-adjustment. No difference was observed in terms of respiratory status at admission, with similar frequencies of dyspnea and oxygen therapy requirement observed in women and men. Plasma glucose and eGFR were similar in both sexes, but men exhibited an exacerbated inflammatory response compared to women, with higher plasma levels of C-reactive protein (CRP) and lactate dehydrogenase (LDH), as well as lower lymphocyte and platelet counts than women.

\section{Influence of sex on COVID-19 outcomes}

The incidence of COVID-19 outcomes in women and men at D7 and D28 is shown in Table 3. In univariate analysis, female sex was inversely associated with the primary composite outcome (IMV and/or death), IMV and ICU admission at both time points, and positively associated with home discharge at D28. Of note, the median length of stay before discharge, analyzed at D28, was similar in both sexes (10.4 \pm 6.1 days in women vs $10.5 \pm 6.4$ in men). After multiple adjustments for confounding factors, female sex was negatively associated with the primary composite outcome (OR 0.66 [0.49-0.88]), death (OR 0.49 [0.300.79]) and ICU admission (OR 0.57 [0.43-0.77]) at D7. At D28, only ICU admission (OR $0.58[0.43-0.77])$ remained significantly associated with female sex in the multivariable model.

Obesity has been associated with an increased risk of severe outcomes in people hospitalized for COVID-19, including those with T2D $(17,18)$. Therefore, we analyzed the incidence of the primary composite outcome and its separate components at D28 in women 
and men according to BMI categories $\left(<25 \mathrm{~kg} / \mathrm{m}^{2}, 25-29.9 \mathrm{~kg} / \mathrm{m}^{2}\right.$ and $\left.\geq 30 \mathrm{~kg} / \mathrm{m}^{2}\right)$ (Table 4). The primary composite outcome and death were not influenced by overweight or obesity status, irrespective of sex. In contrast, in the multivariable model, men with overweight (OR 2.23 [1.37-3.63]) or obesity (OR 2.30 [1.39-3.80]) exhibited an increased risk of IMV compared to those with BMI $<25 \mathrm{~kg} / \mathrm{m}^{2}$. In women, the association between obesity and IMV was no longer significant after multiple adjustment (OR $1.51[0.70-3.29])$, suggesting that, among people with diabetes, men are more susceptible than women to the worsening effect of obesity on COVID-19 respiratory failure.

\section{Sex-dependent predictors of COVID-19 mortality at D28}

We assessed predictive factors of COVID-19 death at D28 in men and women separately to determine whether some of them could be sexually dimorphic. The first multivariable model included the main patient characteristics prior to admission (Figure 1A). After multiple adjustments, older age and a history of microvascular complications were associated with a greater risk of death in both sexes, while COPD was a predictor of death in women only. $\mathrm{HbA}_{1 \mathrm{c}}$ was not included in this model but age- and BMI-adjusted logistic regression analyses revealed that $\mathrm{HbA}_{1 \mathrm{c}}$ was not associated with COVID-19 mortality, neither in women nor in men (Supplemental Figure 2A). A sensitivity analysis was further performed to assess the influence of routine treatments previously suspected to interfere with COVID-19 course (metformin, insulin, DPP4-inhibitors and statins) (19), providing similar results. Of note, metformin was associated with a lower risk of death at D28 in men only, whereas insulin therapy was associated with an increased risk of death at D28 in women only (Supplemental

\section{Tables 2 and 3).}

The second multivariable model included age, BMI and the main biological parameters at admission. Increase in plasma CRP and AST levels, as well as decrease in eGFR, were 
associated with the occurrence of death at D28 in both men and women (Figure 1B). Notably, a decreased lymphocyte count was an independent predictor of death in women only. In contrast, a decreased platelet count and increased plasma glucose were independent predictors of death in men only. Accordingly, in age- and BMI-adjusted linear analysis, admission plasma glucose was also positively associated with death in men $(p=0.007)$ but not in women $(p=0.184)($ Supplemental Figure 2B).

To further investigate the sex-specific association between biomarkers at admission and death at D28, we used cut-off values previously described to correlate with increased COVID19 severity or mortality (CRP, LDH, lymphocyte count) $(20,21)$ or recognized as clinically relevant (platelet count, eGFR, plasma glucose, AST) (Figure 2). After multiple adjustments and consistent with the previous model, lymphocytopenia $\left(<1000 / \mathrm{mm}^{3}\right)$ was an independent predictor of death in women only while high plasma glucose at admission ( $>180 \mathrm{mg} / \mathrm{dL})$ was predictive of death in men only. Increased plasma concentrations of LDH (> 365 IU/L), CRP $(>41.2 \mathrm{mg} / \mathrm{L})$ and $\mathrm{AST}(>3 \mathrm{ULN})$, as well as decreased eGFR values (CKD-EPI, $<60$ $\mathrm{mL} / \mathrm{min} / 1.73 \mathrm{~m}^{2}$ ), were independent predictors of death at D28 in both sexes. 


\section{DISCUSSION}

The present analysis from the nationwide CORONADO study reveals sex differences in clinical and biological features of patients with diabetes hospitalized for COVID-19, as well as early predictors of COVID-19 severe outcomes. Indeed, female sex was associated with a lower risk of COVID-19-related severe outcomes at D7 (i.e. primary composite outcome, death and ICU admission), while sex did not influence death at D28. In addition, we identified sex-associated determinants of death at D28, namely COPD and lymphopenia in women versus thrombocytopenia and elevated admission plasma glucose in men.

The CORONADO population was characterized by a male predominance, with men accounting for almost two third of all people with diabetes hospitalized for COVID-19, as previously described regardless of diabetic status $(9,22)$. This is in agreement with previous reports worldwide in which male sex was associated with increased hospitalization rate, ICU admission, IMV and mortality $(9,11,13,14)$. In a recent meta-analysis including $3,111,714$ COVID-19 cases, Peckham et al. confirmed that men are more prone to ICU admission (OR $2.84[2.06-3.92])$ and death (OR 1.39 [1.31-1.47]) compared to women (23). Data from the whole Scottish population also revealed an association between male sex and severe COVID19 (fatal or requiring ICU admission) in people with diabetes (15).

Hospitalized women with COVID-19 were older than men, exhibited a higher prevalence of obesity and reported digestive symptoms more frequently than men, which is consistent with a recent study in hospitalized COVID-19 patients from New Orleans (24). In our population, the worse prognosis associated with male sex was observed at D7, but was no longer statistically significant at D28, especially when considering mortality. This suggests that diabetes mitigates sex differences by increasing COVID-19 mortality in women, although we cannot exclude a lack of power to explain our results. Consistent with the first possibility, a report from the UK Biobank cohort indicates that diabetes similarly increased the risk of 
fatal COVID-19 in women and men (16). Moreover, in hospitalized COVID-19 patients from New Orleans, diabetes was identified as an independent predictor of in-hospital death in women only (24). Taken together, these observations suggest that diabetes eliminates the female protection from severe COVID-19, at least in people who require hospital admission. Further studies including patients with and without diabetes are required to definitely establish whether diabetes blunts the relative female protection from severe COVID-19 outcomes in patients admitted to hospital.

In our population, women were older and more frequently affected by obesity. Obesity has been recognized as an independent factor for severe COVID-19 outcomes (14, 25, 26), but we found that overweight and obesity were both associated with IMV at D28 in men only. In contrast, in line with our recent findings at D7 (18), BMI status did not influence death at D28, disregarding the sex. Altogether, these observations confirm that an increased BMI promotes severe respiratory disorders rather than death, and suggest that men are more susceptible than women to the worsening effect of obesity on COVID-19 respiratory failure. Of note, women included in CORONADO were less likely than men to be former or current smokers, resulting in a lower prevalence of COPD than in men, which is consistent with previous reports (27). However, COPD was an independent predictor of death in women only. Similarly, in the New Orleans series, in which diabetes prevalence in women was over 38\%, COPD was an independent predictor of ICU admission and IMV requirement in women only (24). Thus, greater attention in the detection and management of this respiratory disease in women with or without diabetes is necessary.

Among patient characteristics prior to hospitalization, the present data confirmed that older age and microvascular complications must be considered as predictive factors of death in both sexes, as recently demonstrated in the whole CORONADO population (28). At admission, inflammatory biomarkers (CRP, LDH and AST), as well as decreased eGFR, were 
also predictors of death at D28 in both sexes. Although women exhibited higher lymphocyte count than men at admission, a decreased lymphocyte count and lymphopenia (lymphocytes < $1000 / \mathrm{mm} 3$ ) were predictors of death in women only. This is consistent with results reported in inpatients from New Orleans, where an elevated neutrophil-to-lymphocyte ratio was an independent predictor of death in women only (24). Since women were reported to exhibit enhanced adaptive immune responses and antibodies production to viral infections $(29,30)$, our observation suggests that lymphopenia may be more deleterious on COVID-19 outcomes in women than in men. In contrast, a decreased platelet count was associated with mortality in men only. Thrombocytopenia has already been described as a predictor of severe COVID-19 outcomes (31). Since men are at increased risk of venous thromboembolism (VTE) compared to women $(32,33)$ and coagulopathies resulting in disseminated intravascular coagulation are a major cause of COVID-19 deaths (34), thrombocytopenia could be a consequence of lethal thrombotic complications in men with diabetes (35). Accordingly, in the New Orleans series, elevated D-dimer, a marker of increased coagulation, was an independent predictor of ICU admission and death in men only (24).

Poor glycemic control during hospitalization has been already linked to severe COVID-19 outcomes in patients with diabetes (36), and fasting blood glucose was associated with mortality in individuals without known diabetes prior to hospitalization (37). However, sex stratification was not considered in these studies. Here, elevated plasma glucose level at admission, but not $\mathrm{HbA}_{1 \mathrm{c}}$, was a predictor of fatal COVID-19 in men, but not in women. This is also in agreement with recent observations $(17,38)$, and confirms that glucose level at admission is a stronger predictor of COVID-19 severity in patients requiring hospitalization than chronic glucose control assessed by $\mathrm{HbA}_{1 \mathrm{c}}$, at least in men.

Prior-to-admission treatment with drugs previously suggested to influence COVID-19 course (metformin, insulin, DPP4-inhibitors and statins) did not modify our findings in terms 
of sex-associated predictive factors of death at D28. However, our results suggested that some of these therapies could alter COVID-19 outcomes differently in women and men. Thus, the reduced risk of death associated with metformin use, already reported in the whole CORONADO population $(28,39)$, was only observed in men. This contrasts with a recent retrospective study suggesting that metformin is associated with better survival specifically in women (40). There is thus a need for further studies to definitely characterize the sex-specific benefits of metformin in COVID-19 patients with T2D. While DPP4-inhibitors appeared to be neutral in both sexes, as reported in the whole population (41), insulin therapy was associated with higher COVID-19 mortality in women only. Apart from CORONADO, the association of previous insulin therapy with severe COVID-19 outcomes has already been reported in patients with T2D (42). Here, the association of insulin therapy with mortality in women likely reflects a more severe burden of comorbidities in women rather than a direct effect of insulin.

The underlying biological mechanisms of sex disparities in COVID-19 severity and mortality still need to be clarified. It is established that biological sex enhances immune responses to viral infections in females through the combined effects of $\mathrm{X}$-linked genes and female hormones, which attenuate innate immune inflammatory response and enhance immune tolerance and antibody production $(29,30,43)$. Male patients seem to exhibit higher plasma levels of innate immune cytokines, along with a more robust induction of non-classical monocytes, while women develop more robust $\mathrm{T}$ cell activation during SARS-CoV-2 infection (44). Accordingly, in CORONADO, men exhibited higher levels of inflammatory markers than women at admission, which could explain their higher susceptibility to severe outcomes during the first week of hospitalization. Further investigations are needed to better understand the interactions between sex and diabetes in immune responses and metainflammation leading to severe COVID-19 (3). 
To our knowledge, this is the first study to investigate sex differences in COVID-19 presentation and severe outcomes in a large population of individuals with diabetes. However, several limitations must be acknowledged. First, since the CORONADO study focused on COVID-19 inpatients with diabetes, our conclusions cannot be generalized to all COVID-19 patients with diabetes. Also, in absence of non-diabetic control group, we were unable to determine whether male sex differently impacts COVID-19 outcomes in people with and without diabetes, as recently suggested (16). Moreover, the observational nature of the present post-hoc analysis did not allow us to draw conclusions on causal relationships between comorbidities, biomarkers, routine treatments and COVID-19 outcomes. Although death at D28 appeared as the most clinically relevant and robust COVID-19 outcome, the sex stratification limited the power of statistical analyses, especially in women. Additionally, we were unable to perform analyses according to menopausal status due to the small number of women under 50 years in the CORONADO population and to the very low incidence of COVID-19-related events in this subgroup. Finally, our results are hampered by missing data, especially for $\mathrm{HbA}_{1 \mathrm{c}}$ and other biological markers such as $\mathrm{LDH}$, and the lack of systematic collection of data regarding COVID-19 therapies during hospitalization.

In conclusion, in France, female sex was associated with lower incidence of early severe outcomes including death in patients with diabetes admitted for COVID-19. However, sex did not influence the overall mortality during hospital stay, suggesting that diabetes mitigates sex differences in COVID-19 severity. At admission, sex-associated biological determinants of COVID-19 death, namely lymphopenia in women and both hyperglycemia and thrombocytopenia in men, should be considered to optimize prevention and management strategies in women and men. 


\section{ACKNOWLEDGEMENTS}

We thank the sponsor (DRCI CHU Nantes) Clinical Project Manager (Maëva Saignes) and assistant (Jeanne Saunier), Clinical Research Associates (Selma El Andaloussi, Joëlle MartinGauthier, Emily Rebouilleau) and data manager (Tanguy Roman). We thank the Communication Manager of l'Institut du Thorax (Vimla Mayoura). We acknowledge all medical staff involved in the diagnosis and treatment of patients with COVID-19 in participating centers. We thank all GPs, specialists, pharmacists and biological laboratories in charge of hospitalized patients for providing additional medical information to our investigators. We thank the Société Francophone du Diabète (SFD) and Société Française d'Endocrinologie (SFE) for disseminating study design and organization, the Fédération Française des Diabétiques (FFD) for participating in the study organisation.

\section{Authors contributions}

BT, SS, SC, MW, JFG, BC, FMJ and PG designed the study. All co-authors contributed to patient recruitment, data collection and/or data management. SC and MW performed the statistical analyses. BT, SS, SC, FMJ and PG drafted the first version of the manuscript. All co-authors critically reviewed and edited the manuscript. BC, PG, SH and MP conducted the fundraising of the study.

\section{Guarantor's name}

$\mathrm{BC}, \mathrm{SH}$ and $\mathrm{MW}$ are the guarantors of this work and, as such, had full access to all the data in the study and take responsibility for the integrity of the data and the accuracy of the data analysis. The corresponding authors (FMJ and PG) had full access to all the data in the study and had final responsibility for the decision to submit for publication. 


\section{Funding}

This study received the following funding: the Fondation Francophone de Recherche sur le Diabète (FFRD), supported by Novo Nordisk, MSD, Abbott, AstraZeneca, Lilly and FFD (Fédération Française des Diabétiques) - CORONADO initiative emergency grant; Société Francophone du Diabète (SFD) - CORONADO initiative emergency grant; Air Liquide Health Care international. CORONADO initiative emergency grant; Allergan. CORONADO initiative emergency grant; AstraZeneca. CORONADO initiative emergency grant; Elivie. CORONADO initiative emergency grant; Fortil. CORONADO initiative emergency grant; Lifescan. CORONADO initiative emergency grant; CORONADO initiative emergency grant; Nantes Métroplole. NHC. CORONADO initiative emergency grant; Novo Nordisk. CORONADO initiative emergency grant; Sanofi. CORONADO emergency grant; PHRC National COVID-19 Hospitalization and Care Organization Division (DHOS) as part of the Hospital Clinical Research Program (PHRC COVID-19-20-0138). FMJ was funded by National Institutes of Health awards (DK074970 and DK107444), an American Diabetes Association COVID-19 Research Award (7-20-COVID-051), a US Department of Veterans Affairs Merit Review Award (BX003725) and the Tulane Center of Excellence in Sex-Based Biology \& Medicine. All research facilities are acknowledged for providing research associates and research technicians for clinical investigations pro bono. The funders of the study had no role in study design, data collection, data analysis, data interpretation, or writing of the report.

\section{Conflict of interest statement}

MW reports grants, personal fees from Air Liquid, Allergan, Elivie, Fortil, Lifescan, NHC, Novo Nordisk, and Sanofi.

MP reports grants, non-financial support or personal fees from Air Liquid, Allergan, Amgen, Elivie, Fortil, Lifescan, NHC, Novo Nordisk, and Sanofi.

AAS reports personal fees from AstraZeneca and Novo Nordisk. 
LB non-financial support or personal fees from Abbott, Astra Zeneca, Becton Dickinson, Boehringer Ingelheim, Eli Lilly, MSD, Novartis, Novo Nordisk, and Sanofi.

EC reports non-financial support or personal fees from Abbott, AlphaDiab, Air Liquide, Ascencia, Astra Zeneca, Bezins, BMS, Eli Lilly, LifeScan, Medtronic, MSD, Novartis, NovoNordisk, Roche Diagnostics, Sanofi, and YpsoMed.

MM reports personal fees from Novo-Nordisk, Servier, and MSD.

LP reports personal fees or non-financial support from, Eli Lilly, MSD, Novo Nordisk and Sanofi

JFG reports personal fees and non-financial support from Eli Lilly, personal fees and nonfinancial support from Novo Nordisk, personal fees and non-financial support from Gilead, and personal fees and non-financial support from AstraZeneca.

SH reports grants, non-financial support or personal fees from Air Liquid, Allergan, Astra Zeneca, Bayer, Boehringer Ingelheim, Dinno Santé, Eli Lilly, Elivie, Fortil, Lifescan, LVL, Merck Sharpe Dome, NHC, Novartis, Pierre Fabre Santé, Sanofi, Servier, and Valbiotis.

BC reports grants, non-financial support or personal fees from Abbott, Allergan, Amgen, Akcea AstraZeneca, Pierre Fabre, Genfit, Gilead, Eli Lilly, Elivie, Fortil, Lifescan, Merck Sharpe Dome, NHC, Novo Nordisk, Regeneron and Sanofi.

PG reports grants or personal fees from Abbott, Air Liquid, Allergan, Amgen, Astra-Zeneca, Boehringer Ingelheim, Eli Lilly, Elivie, Fortil, Lifescan, Merck Sharp and Dohme, Mundipharma, NHC, Novo Nordisk, Sanofi, and Servier.

Other authors report no conflict of interest. 


\section{REFERENCES}

1. Singh AK, Gillies CL, Singh R, Singh A, Chudasama Y, Coles B, Seidu S, Zaccardi F, Davies MJ, \& Khunti K. Prevalence of co-morbidities and their association with mortality in patients with COVID-19: A systematic review and meta-analysis. Diabetes, Obesity and Metabolism 2020 . (doi:10.1111/dom.14124)

2. Lim S, Bae JH, Kwon HS, \& Nauck MA. COVID-19 and diabetes mellitus: from pathophysiology to clinical management. Nature Reviews Endocrinology2021. pp 1130. . (doi:10.1038/s41574-020-00435-4)

3. Mauvais-Jarvis F. Aging, male sex, obesity, and metabolic inflammation create the perfect storm for COVID-19. Diabetes 202069 1857-1863. (doi:10.2337/dbi19-0023)

4. Klein SL \& Flanagan KL. Sex differences in immune responses. Nature Reviews Immunology2016. pp 626-638. . (doi:10.1038/nri.2016.90)

5. Karlberg J, Chong DSY, \& Lai WYY. Do Men Have a Higher Case Fatality Rate of Severe Acute Respiratory Syndrome than Women Do? American Journal of Epidemiology 2004159 229-231. (doi:10.1093/aje/kwh056)

6. Alghamdi IG, Hussain II, Almalki SS, Alghamdi MS, Alghamdi MM, \& El-Sheemy MA. The pattern of Middle east respiratory syndrome coronavirus in Saudi Arabia: A descriptive epidemiological analysis of data from the Saudi Ministry of Health. International Journal of General Medicine 20147 417-423. (doi:10.2147/IJGM.S67061)

7. Klein SL, Dhakal S, Ursin RL, Deshpande S, Sandberg K, \& Mauvais-Jarvis F. Biological sex impacts COVID-19 outcomes. PLoS Pathogens 202016. 
(doi:10.1371/journal.ppat.1008570)

8. Gebhard C, Regitz-Zagrosek V, Neuhauser HK, Morgan R, \& Klein SL. Impact of sex and gender on COVID-19 outcomes in Europe. Biology of Sex Differences2020. (doi:10.1186/s13293-020-00304-9)

9. Guan W jie, Ni Z yi, Hu Y, Liang W hua, Ou C quan, He J xing, Liu L, Shan H, Lei C liang, Hui DSC et al. Clinical Characteristics of Coronavirus Disease 2019 in China. New England Journal of Medicine 2020 . (doi:10.1056/nejmoa2002032)

10. Internet. This is Gender 2021 - Global Health 50/50.

11. Grasselli G, Zangrillo A, Zanella A, Antonelli M, Cabrini L, Castelli A, Cereda D, Coluccello A, Foti G, Fumagalli R et al. Baseline Characteristics and Outcomes of 1591 Patients Infected With SARS-CoV-2 Admitted to ICUs of the Lombardy Region, Italy. JAMA 2020 . (doi:10.1001/jama.2020.5394)

12. ICNARC. Report on COVID-19 in critical care. Intensive Care National Audit \& Research Centre2020. pp 1-24. .

13. Suleyman G, Fadel RA, Malette KM, Hammond C, Abdulla H, Entz A, Demertzis Z, Hanna Z, Failla A, Dagher C et al. Clinical Characteristics and Morbidity Associated With Coronavirus Disease 2019 in a Series of Patients in Metropolitan Detroit. JAMA network open 20203 e2012270. (doi:10.1001/jamanetworkopen.2020.12270)

14. Williamson EJ, Walker AJ, Bhaskaran K, Bacon S, Bates C, Morton CE, Curtis HJ, Mehrkar A, Evans D, Inglesby P et al. Factors associated with COVID-19-related death using OpenSAFELY. Nature 2020584 430-436. (doi:10.1038/s41586-0202521-4) 
15. McGurnaghan SJ, Weir A, Bishop J, Kennedy S, Blackbourn LAK, McAllister DA, Hutchinson S, Caparrotta TM, Mellor J, Jeyam A et al. Risks of and risk factors for COVID-19 disease in people with diabetes: a cohort study of the total population of Scotland. The Lancet Diabetes and Endocrinology 20219 82-93. (doi:10.1016/S2213$8587(20) 30405-8)$

16. Jong M de, Woodward M, \& Peters SAE. Diabetes and COVID-19-Related Mortality in Women and Men in the UK Biobank: Comparisons With Influenza/Pneumonia and Coronary Heart Disease. Diabetes care 2020 . (doi:10.2337/dc20-2378)

17. Cariou B, Hadjadj S, Wargny M, Pichelin M, Al-Salameh A, Allix I, Amadou C, Arnault G, Baudoux F, Bauduceau B et al. Phenotypic characteristics and prognosis of inpatients with COVID-19 and diabetes: the CORONADO study. Diabetologia 2020 63 1500-1515. (doi:10.1007/s00125-020-05180-x)

18. Smati S, Tramunt B, Wargny M, Caussy C, Gaborit B, Vatier C, Vergès B, Ancelle D, Amadou C, Bachir LA et al. Relationship between obesity and severe COVID-19 outcomes in patients with type 2 diabetes: Results from the CORONADO study. Diabetes, Obesity and Metabolism 202123 391-403. (doi:10.1111/dom.14228)

19. Drucker DJ. Diabetes, obesity, metabolism, and SARS-CoV-2 infection: the end of the beginning. Cell Metabolism2021. pp 479-498. . (doi:10.1016/j.cmet.2021.01.016)

20. Xie J, Zu Y, Alkhatib A, Pham TT, Gill F, Jang A, Radosta S, Chaaya G, Myers L, Zifodya JS et al. Metabolic Syndrome and COVID-19 Mortality Among Adult Black Patients in New Orleans. Diabetes Care 2020 dc201714. (doi:10.2337/dc20-1714)

21. Trecarichi EM, Mazzitelli M, Serapide F, Pelle MC, Tassone B, Arrighi E, Perri G, 
Fusco P, Scaglione V, Davoli C et al. Clinical characteristics and predictors of mortality associated with COVID-19 in elderly patients from a long-term care facility. Scientific Reports 202010 . (doi:10.1038/s41598-020-77641-7)

22. Zhu W, Xie K, Lu H, Xu L, Zhou S, \& Fang S. Initial clinical features of suspected coronavirus disease 2019 in two emergency departments outside of Hubei, China. Journal of Medical Virology 202092 1525-1532. (doi:10.1002/jmv.25763)

23. Peckham H, Gruijter N De, Raine C, Radziszewska A, Ciurtin C, Wedderburn L, Rosser E, Deakin C, \& Webb K. Male sex identified by global COVIS-19 metaanalysis as a risk factor for death and ITU admission. Nature Communications 202011 6317. (doi:10.21203/rs.3.rs-23651/v2)

24. Yoshida Y, Gillet SA, Brown MI, Zu Y, Wilson SM, Ahmed SJ, Tirumalasetty S, Lovre D, Krousel-Wood M, Denson JL et al. Clinical characteristics and outcomes in women and men hospitalized for coronavirus disease 2019 in New Orleans. Biology of Sex Differences 202112 20. (doi:10.1186/s13293-021-00359-2)

25. Tartof SY, Qian L, Hong V, Wei R, Nadjafi RF, Fischer H, Li Z, Shaw SF, Caparosa SL, Nau CL et al. Obesity and Mortality Among Patients Diagnosed With COVID-19: Results From an Integrated Health Care Organization. Annals of Internal Medicine 2020 M20-3742. (doi:10.7326/M20-3742)

26. Caussy C, Pattou F, Wallet F, Simon C, Chalopin S, Telliam C, Mathieu D, Subtil F, Frobert E, Alligier M et al. Prevalence of obesity among adult inpatients with COVID19 in France. The Lancet Diabetes \& Endocrinology 2020 0 . (doi:10.1016/S22138587(20)30160-1) 
27. Mauvais-Jarvis F, Bairey Merz N, Barnes PJ, Brinton RD, Carrero JJ, DeMeo DL, Vries GJ De, Epperson CN, Govindan R, Klein SL et al. Sex and gender: modifiers of health, disease, and medicine. The Lancet2020. pp 565-582. . (doi:10.1016/S0140$6736(20) 31561-0)$

28. Wargny M, Potier L, Gourdy P, Pichelin M, Amadou C, Benhamou PY, Bonnet JB, Bordier L, Bourron O, Chaumeil C et al. Predictors of hospital discharge and mortality in patients with diabetes and COVID-19: updated results from the nationwide CORONADO study. Diabetologia 202164 778-794. (doi:10.1007/s00125-020-05351w)

29. Scully EP, Haverfield J, Ursin RL, Tannenbaum C, \& Klein SL. Considering how biological sex impacts immune responses and COVID-19 outcomes. Nature Reviews Immunology 202020 442-447. (doi:10.1038/s41577-020-0348-8)

30. Bunders MJ \& Altfeld M. Implications of Sex Differences in Immunity for SARSCoV-2 Pathogenesis and Design of Therapeutic Interventions. Immunity2020. pp 487495. . (doi:10.1016/j.immuni.2020.08.003)

31. Yang X, Yang Q, Wang Y, Wu Y, Xu J, Yu Y, \& Shang Y. Thrombocytopenia and its association with mortality in patients with COVID-19. Journal of Thrombosis and Haemostasis 202018 1469-1472. (doi:10.1111/jth.14848)

32. Baglin T, Luddington R, Brown K, \& Baglin C. High risk of recurrent venous thromboembolism in men. Journal of Thrombosis and Haemostasis 20042 2152-2155. (doi:10.1111/j.1538-7836.2004.01050.x)

33. Eichinger S, Heinze G, Jandeck LM, \& Kyrle PA. Risk assessment of recurrence in 
patients with unprovoked deep vein thrombosis or pulmonary embolism: The vienna prediction model. Circulation 2010121 1630-1636.

(doi:10.1161/CIRCULATIONAHA.109.925214)

34. Zhou F, Yu T, Du R, Fan G, Liu Y, Liu Z, Xiang J, Wang Y, Song B, Gu X et al. Clinical course and risk factors for mortality of adult inpatients with COVID-19 in Wuhan, China: a retrospective cohort study. The Lancet 2020395 1054-1062. (doi:10.1016/S0140-6736(20)30566-3)

35. Tang N, Li D, Wang X, \& Sun Z. Abnormal coagulation parameters are associated with poor prognosis in patients with novel coronavirus pneumonia. Journal of Thrombosis and Haemostasis 202018 844-847. (doi:10.1111/jth.14768)

36. Zhu L, She ZG, Cheng X, Qin JJ, Zhang XJ, Cai J, Lei F, Wang H, Xie J, Wang W et al. Association of Blood Glucose Control and Outcomes in Patients with COVID-19 and Pre-existing Type 2 Diabetes. Cell Metabolism 2020 1-10. (doi:10.1016/j.cmet.2020.04.021)

37. Wang S, Ma P, Zhang S, Song S, Wang Z, Ma Y, Xu J, Wu F, Duan L, Yin Z et al. Fasting blood glucose at admission is an independent predictor for 28-day mortality in patients with COVID-19 without previous diagnosis of diabetes: a multi-centre retrospective study. Diabetologia 202063 2102-2111. (doi:10.1007/s00125-02005209-1)

38. Agarwal S, Schechter C, Southern W, Crandall JP, \& Tomer Y. Preadmission diabetesspecific risk factors for mortality in hospitalizedpatients withdiabetes and coronavirus disease 2019. Diabetes Care 202043 2339-2344. (doi:10.2337/dc20-1543) 
39. Lalau JD, Al-Salameh A, Hadjadj S, Goronflot T, Wiernsperger N, Pichelin M, Allix I, Amadou C, Bourron O, Duriez T et al. Metformin use is associated with a reduced risk of mortality in patients with diabetes hospitalised for COVID-19. Diabetes \& Metabolism 2020 101216. (doi:10.1016/j.diabet.2020.101216)

40. Bramante CT, Ingraham NE, Murray TA, Marmor S, Hovertsen S, Gronski J, McNeil C, Feng R, Guzman G, Abdelwahab N et al. Observational study of metformin and risk of mortality in patients hospitalized with Covid-19. medRxiv2020. (doi:10.1101/2020.06.19.20135095)

41. Roussel R, Darmon P, Pichelin M, Goronflot T, Abouleka Y, Ait Bachir L, Allix I, Ancelle D, Barraud S, Bordier L et al. Use of Dipeptidyl Peptidase-4 inhibitors and prognosis of COVID-19 in hospitalized patients with type 2 diabetes: a propensity score analysis from the CORONADO study. Diabetes, obesity \& metabolism 2021 . (doi:10.1111/dom.14324)

42. Yu B, Li C, Sun Y, \& Wang DW. Insulin Treatment Is Associated with Increased Mortality in Patients with COVID-19 and Type 2 Diabetes. Cell Metabolism 202133 65-77.e2. (doi:10.1016/j.cmet.2020.11.014)

43. Mauvais-Jarvis F, Klein SL, \& Levin ER. Estradiol, Progesterone, Immunomodulation, and COVID-19 Outcomes. Endocrinology (United States)2020.

(doi:10.1210/endocr/bqaa127)

44. Takahashi T, Ellingson MK, Wong P, Israelow B, Lucas C, Klein J, Silva J, Mao T, Oh JE, Tokuyama M et al. Sex differences in immune responses that underlie COVID-19 disease outcomes. Nature 2020588 315-320. (doi:10.1038/s41586-020-2700-3) 


\section{FIGURE LEGENDS}

\section{Figure 1. Sex-associated predictive factors of COVID-19-related death at day 28}

Multivariable analysis of death at D28: covariates prior to (Model A) and at admission (Model B). Model A was applied to 541 women and 891 men yielding respectively 80 and 164 deaths at 28 days. Model B was applied to 533 women and 911 men yielding respectively 79 and 175 deaths at 28 days Regarding quantitative variables: all were natural-log transformed, except for age, and the ORs correspond to an increase of 1 SD after standardization. BMI: Body Mass Index; Microvascular complications correspond to severe diabetic retinopathy, diabetic kidney disease and/or history of diabetic foot ulcer; macrovascular complications correspond to ischemic heart disease, cerebrovascular disease and/or peripheral artery disease; COPD: Chronic Obstructive Pulmonary Disease; OSA: Obstructive Sleep Apnea; eGFR was determined by the CKD-EPI formula. AST: Aspartate AminoTransferase; ULN, upper limit of normal; OR: Odds Ratio; 95\% CI: 95\% confidence interval; SD: Standard Deviation.

\section{Figure 2. Association of biological markers on admission with COVID-19-related death}

\section{at day 28 according to sex.}

Values are stratified according to cut-off values previously shown to correlate with increased disease severity or mortality in COVID-19 or clinically relevant (lymphocytes $<1000 / \mathrm{mm}^{3}$; platelets $<150 \times 10^{3} / \mu 1 ;$ CRP $>41.2 \mathrm{mg} / \mathrm{L} ; \quad \mathrm{LDH}>365 \mathrm{IU} / \mathrm{L} ; \quad \mathrm{eGFR}<60 \mathrm{~mL} / \mathrm{min} / 1.73 \mathrm{~m}^{2}$; AST>3ULN).

OR: Odds Ratio; 95\% CI: 95\% confidence interval; SD: Standard Deviation; Nm: number of men included in the model; Nw: number of women included in the model; LDH: Lactate DeHydrogenase; CRP: C-Reactive Protein; eGFR: estimated Glomerular Filtration Rate, according to the CKD-EPI formula; AST: Aspartate AminoTransferase; ULN: Upper Limit of Normal. 
Multi-adjustment on age, BMI, smoking, microvascular complications, macrovascular complications, hypertension, COPD and treated OSA. 
Table 1. Clinical characteristics of CORONADO participants prior to admission according to sex. Data are presented as $n(\%)$ or median (25 ${ }^{\text {th }} ; 5^{\text {th }}$ percentile). Associated $P$-values are given using Wald tests (logistic regression model not adjusted and adjusted for age).

\begin{tabular}{|c|c|c|c|c|c|}
\hline Clinical features & All & Women & Men & $P$-value & $\begin{array}{c}\text { Age-adjusted } \\
P \text {-value }\end{array}$ \\
\hline Total, $n$ & 2380 & 868 & 1512 & & \\
\hline Age (y) & $70(61 ; 79)$ & $71(61 ; 81)$ & $69(60 ; 78)$ & 0.001 & \\
\hline Age categories, $n$ & 2380 & 868 & 1512 & $<0.001$ & \\
\hline \begin{tabular}{l|l|} 
& $<50 \mathrm{y}$ \\
\end{tabular} & $183(7.7 \%)$ & $68(7.8 \%)$ & $115(7.6 \%)$ & & 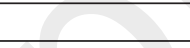 \\
\hline $50-59 y$ & $349(14.7 \%)$ & $119(13.7 \%)$ & $230(15.2 \%)$ & 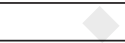 & \\
\hline $60-69 y$ & $634(26.6 \%)$ & $207(23.8 \%)$ & $427(28.2 \%)$ & & 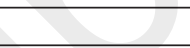 \\
\hline $70-79 y$ & $655(27.5 \%)$ & $218(25.1 \%)$ & $437(28.9 \%)$ & - & 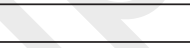 \\
\hline$>80 y$ & $559(23.5 \%)$ & $256(29.5 \%)$ & $303(20.0 \%)$ & 4 & +2 \\
\hline $\operatorname{BMI}\left(\mathrm{kg} / \mathrm{m}^{2}\right)$ & $28.4(25.1 ; 32.4)$ & $29.8(25.7 ; 34.5)$ & $27.8(24.9 ; 31.2)$ & $<0.001$ & $<0.001$ \\
\hline BMI classes, $n$ & 2380 & 868 & 1512 & $<0.001$ & $<0.001$ \\
\hline \begin{tabular}{l|l} 
& $<25 \mathrm{~kg} / \mathrm{m}^{2}$
\end{tabular} & $587(24.7 \%)$ & $190(21.9 \%)$ & $397(26.3 \%)$ & & \\
\hline $25-29.9 \mathrm{~kg} / \mathrm{m}^{2}$ & $864(36.3 \%)$ & $251(28.9 \%)$ & $613(40.5 \%)$ & 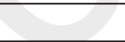 & \\
\hline$\geq 30 \mathrm{~kg} / \mathrm{m}^{2}$ & $929(39.0 \%)$ & $427(49.2 \%)$ & $502(33.2 \%)$ & & \\
\hline Ethnicity, $n$ & 2031 & 740 & 1291 & 0.385 & 0.173 \\
\hline \begin{tabular}{l|l} 
& $\mathrm{EU}$ \\
\end{tabular} & $1179(58.1 \%)$ & $436 /(58.9 \%)$ & $743(57.6 \%)$ & & \\
\hline MENA & $416 /(20.5 \%)$ & $138(18.6 \%)$ & $278(21.5 \%)$ & & \\
\hline $\mathrm{AC}$ & $361 /(17.8 \%)$ & $140(18.9 \%)$ & $221(17.1 \%)$ & & \\
\hline \begin{tabular}{l|l} 
AS \\
\end{tabular} & $75(3.7 \%)$ & $26(3.5 \%)$ & $49(3.8 \%)$ & & \\
\hline Diabetes classification, $n$ & 2380 & 868 & 1512 & 0.472 & 0.220 \\
\hline \begin{tabular}{l|l} 
& Type 2 \\
\end{tabular} & $2086(87.6 \%)$ & $758(87.3 \%)$ & $1328(87.8 \%)$ & & \\
\hline Type 1 & $54(2.3 \%)$ & $24(2.8 \%)$ & $30(2.0 \%)$ & & \\
\hline Others & $240(10.1 \%)$ & $86(9.9 \%)$ & $154(10.2 \%)$ & & \\
\hline Diabetes duration (y), $n=1610$ & $11(5 ; 20)$ & $12(5 ; 20)$ & $11(5 ; 19)$ & 0.235 & 0.299 \\
\hline $\mathrm{HbA}_{1 \mathrm{c}}(\%), n=1580$ & $7.7(6.8 ; 9.0)$ & $7.7(6.9 ; 9.0)$ & $7.7(6.8 ; 9.0)$ & 0.618 & 0.873 \\
\hline Smoking, $n$ & 1994 & 703 & 1291 & $<0.001$ & $<0.001$ \\
\hline Never & $1202(60.3 \%)$ & $606(86.2 \%)$ & $596(46.2 \%)$ & & \\
\hline Former & $674(33.8 \%)$ & $79(11.2 \%)$ & $595(46.1 \%)$ & & \\
\hline \begin{tabular}{l|l} 
& Current \\
\end{tabular} & $118 /(5.9 \%)$ & $18(2.6 \%)$ & $100(7.7 \%)$ & & \\
\hline Microvascular complications, $n$ & 1760 & 668 & 1092 & & \\
\hline & $778(44.2 \%)$ & $300(44.9 \%)$ & $478(43.8 \%)$ & 0.641 & 0.612 \\
\hline Macrovascular complications, $n$ & 2248 & 821 & 1427 & & \\
\hline & $870(38.7 \%)$ & $257(31.3 \%)$ & $613(43.0 \%)$ & $<0.001$ & $<0.001$ \\
\hline Comorbidities & & & & & \\
\hline \begin{tabular}{l|l} 
& Hypertension, $n$ \\
\end{tabular} & 2360 & 859 & 1501 & & \\
\hline & $1817(77.0 \%)$ & $672(78.2 \%)$ & $1145(76.3 \%)$ & 0.279 & 0.854 \\
\hline Dyslipidemia, $n$ & 2320 & 849 & 1471 & & \\
\hline & $1122(48.4 \%)$ & $377(44.4 \%)$ & $745(50.6 \%)$ & 0.004 & 0.001 \\
\hline Heart failure, $n$ & 2268 & 824 & 1444 & & \\
\hline 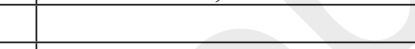 & $272(12.0 \%)$ & $111(13.5 \%)$ & $161(11.1 \%)$ & 0.102 & 0.291 \\
\hline COPD, $n$ & 2329 & 846 & 1483 & & \\
\hline 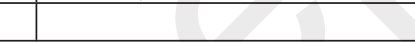 & $228(9.8 \%)$ & $65(7.7 \%)$ & $163(11.0 \%)$ & 0.01 & 0.003 \\
\hline Treated OSA, $n$ & 2217 & 805 & 1412 & & \\
\hline 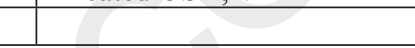 & $245(11.1 \%)$ & $78(9.7 \%)$ & $167(11.8 \%)$ & 0.123 & 0.131 \\
\hline
\end{tabular}

BMI, Body Mass Index; Ethnicity, EU (Europid); MENA, (Middle East North Africa); AC, African or Caribbean); AS, Asian; $\mathrm{HbA}_{1 \mathrm{c}}$ corresponds to the $\mathrm{HbA}_{1 \mathrm{c}}$ value determined in the first 7 days following admission or the most recent value available in the 6 months prior to admission; microvascular complications correspond to severe diabetic retinopathy, diabetic kidney disease and/or history of diabetic foot ulcer; macrovascular complications correspond to ischemic heart disease, cerebrovascular disease and/or peripheral artery disease; COPD: Chronic Obstructive Pulmonary Disease; OSA: Obstructive Sleep Apnea. 
Table 2 Clinical and biological characteristics of CORONADO participants at admission, according to sex. Data are presented as $n$ (\%) or median ( $25^{\text {tht }}$; $75^{\text {th }}$ percentile). Associated $P$-values are given using Wald tests (logistic regression model not adjusted and adjusted for age).

\begin{tabular}{|c|c|c|c|c|c|c|}
\hline COVID-19-related characteristics & $\begin{array}{l}\text { Available } \\
\text { data }\end{array}$ & All & Women & Men & $P$-value & $\begin{array}{l}\text { Age-adjusted } \\
P \text {-value }\end{array}$ \\
\hline Total, $n$ & & 2380 & 868 & 1512 & & \\
\hline Positive SARS-CoV-2 PCR & 2306 & $2189 / 2306(94.9 \%)$ & $792 / 831(95.3 \%)$ & $1397 / 1475(94.7 \%)$ & 0.532 & 0.445 \\
\hline COVID-19 symptoms & 2379 & $2256 / 2379(94.8 \%)$ & $817 / 867(94.2 \%)$ & $1439 / 1512(95.2 \%)$ & 0.320 & 0.494 \\
\hline $\begin{array}{l}\text { Time between symptom onset and hospital } \\
\text { admission (days) }\end{array}$ & 2342 & $5(2 ; 9)$ & $5(2 ; 8)$ & $6(3 ; 9)$ & 0.066 & 0.206 \\
\hline Clinical presentation & & & & 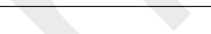 & & \\
\hline \begin{tabular}{l|l} 
Fever \\
\end{tabular} & 2348 & $1782 / 2348(75.9 \%)$ & $623 / 860(72.4 \%)$ & $1159 / 1488(77.9 \%)$ & 0.003 & 0.008 \\
\hline Fatigue & 2274 & $1416 / 2274(62.3 \%)$ & $517 / 830(62.3 \%)$ & $899 / 1444(62.3 \%)$ & 0.988 & 0.733 \\
\hline Cough & 2316 & $1549 / 2316(66.9 \%)$ & $557 / 840(66.3 \%)$ & $992 / 1476(67.2 \%)$ & 0.658 & 0.953 \\
\hline Cephalalgia & 2205 & $307 / 2205(13.9 \%)$ & $122 / 810(15.1 \%)$ & $185 / 1395(13.3 \%)$ & 0.239 & 0.049 \\
\hline Dyspnea & 2345 & $1509 / 2345(64.3 \%)$ & $538 / 860(62.6 \%)$ & $971 / 1485(65.4 \%)$ & 0.168 & 0.212 \\
\hline Oxygen therapy requirement & 1840 & $1214 / 1840(66.0 \%)$ & $441 / 669(65.9 \%)$ & $773 / 1171(66.0 \%)$ & 0.968 & 0.892 \\
\hline Rhinitis and/or pharyngeal signs & 2165 & $193 / 2165(8.9 \%)$ & $72 / 802(9.0 \%)$ & $121 / 1363(8.9 \%)$ & 0.937 & 0.679 \\
\hline Agueusia and/or Anosmia & 2078 & $307 / 2078(14.8 \%)$ & $98 / 755(13.0 \%)$ & $209 / 1323(15.8 \%)$ & 0.082 & 0.211 \\
\hline Digestive disorders & 2273 & $788 / 2273(34.7 \%)$ & $327 / 832(39.3 \%)$ & $461 / 1441(32.0 \%)$ & $<0.001$ & $<0.001$ \\
\hline \multicolumn{7}{|l|}{ Chest CT imaging } \\
\hline Abnormal chest CT & 1701 & $1648 / 1701(96.9 \%)$ & $560 / 580(96.6 \%)$ & $1088 / 1121(97.1 \%)$ & 0.571 & 0.617 \\
\hline Ground-glass opacity/crazy paving & 1678 & $1517 / 1678(90.4 \%)$ & $510 / 572(89.2 \%)$ & $1007 / 1106(91.0 \%)$ & 0.214 & 0.288 \\
\hline \multicolumn{7}{|l|}{ Biological findings } \\
\hline Admission plasma glucose $(\mathrm{mg} / \mathrm{dL})$ & 1772 & $170(127 ; 240)$ & $165(124 ; 234)$ & $172(128 ; 245)$ & 0.167 & 0.303 \\
\hline eGFR (CKD-EPI) $\left(\mathrm{mL} / \mathrm{min} / 1.73 \mathrm{~m}^{2}\right)$ & 2218 & $68.5(41.4 ; 89.7)$ & $67.3(39.0 ; 90.4)$ & $69.1(42.9 ; 89.2)$ & 0.492 & 0.731 \\
\hline ALT $(\%$ ULN $)$ & 2114 & $0.62(0.42 ; 1.00)$ & $0.59(0.40 ; 0.96)$ & $0.64(0.43 ; 1.02)$ & 0.039 & 0.115 \\
\hline AST $(\%$ ULN $)$ & 2086 & $1.06(0.74 ; 1.59)$ & $1.00(0.71 ; 1.46)$ & $1.10(0.76 ; 1.68)$ & 0.008 & 0.013 \\
\hline GGT $(\%$ ULN $)$ & 1980 & $0.95(0.57 ; 1.80)$ & $1.10(0.63 ; 2.12)$ & $0.90(0.53 ; 1.62)$ & $<0.001$ & $<0.001$ \\
\hline Hemoglobin $(\mathrm{g} / \mathrm{dL})$ & 2323 & $12.7(11.4 ; 14.2)$ & $12.1(10.9 ; 13.2)$ & $13.2(11.7 ; 14.6)$ & $<0.001$ & $<0.001$ \\
\hline White cell count $\left(10^{3} / \mathrm{mm}^{3}\right)$ & 2321 & $6500(4970 ; 8800)$ & $6400(4900 ; 8585)$ & $6600(5000 ; 8800)$ & 0.105 & 0.088 \\
\hline Lymphocyte count $\left(10^{3} / \mathrm{mm}^{3}\right)$ & 2249 & $1000(700 ; 1400)$ & $1100(740 ; 1548)$ & $950(670 ; 1305)$ & 0.001 & $<0.001$ \\
\hline Platelet count $\left(10^{3} / \mu \mathrm{l}\right)$ & 2320 & $201(155 ; 259)$ & $217(168 ; 280)$ & $191(149 ; 246)$ & $<0.001$ & $<0.001$ \\
\hline $\mathrm{CRP}(\mathrm{mg} / \mathrm{L})$ & 2217 & $84.5(40.2 ; 147.0)$ & $66.6(31.0 ; 127.0)$ & $96.0(47.0 ; 155.5)$ & $<0.001$ & $<0.001$ \\
\hline $\mathrm{LDH}(\mathrm{IU} / \mathrm{L})$ & 1218 & $346(263 ; 495)$ & $331(256 ; 444)$ & $357(269 ; 515)$ & 0.019 & 0.022 \\
\hline
\end{tabular}

eGFR, estimated Glomerular Filtration Rate according to the CKD-EPI formula; ALT, Alanine AminoTransferase; AST, Aspartate AminoTransferase; GGT, Gamma-Glutamyl Transferase; ULN, Upper Limit of Normal; CRP, C-Reactive Protein; LDH, Lactate DeHydrogenase. 
Table 3. Clinical outcomes at day 7 and day 28 following hospital admission.

\begin{tabular}{|c|c|c|c|c|c|c|c|}
\hline \multirow[t]{2}{*}{ COVID-19-related outcomes } & \multirow[t]{2}{*}{ All } & \multirow[t]{2}{*}{ Women } & \multirow[t]{2}{*}{ Men } & \multicolumn{2}{|c|}{ OR $(95 \% \mathrm{CI})$} & \multirow[t]{2}{*}{$P$-value } & \multirow{2}{*}{$\begin{array}{l}\text { Multi- } \\
\text { adjusted } \\
P \text {-value }\end{array}$} \\
\hline & & & & Unadjusted & Multi adjusted & & \\
\hline Primary composite outcome & $688(28.9 \%)$ & $204(23.5 \%)$ & $484(32.0 \%)$ & $0.65(0.54-0.79)$ & $0.66(0.49-0.88)$ & $<0.001$ & 0.005 \\
\hline Death & $243(10.2 \%)$ & $79(9.1 \%)$ & $164(10.8 \%)$ & $0.82(0.62-1.09)$ & $0.49(0.30-0.79)$ & 0.176 & 0.004 \\
\hline \multicolumn{8}{|l|}{ At 28 days } \\
\hline Primary composite outcome & $844(35.5 \%)$ & $265(30.5 \%)$ & $579(38.3 \%)$ & $0.71(0.59-0.85)$ & $0.77(0.59-1.01)$ & $<0.001$ & 0.059 \\
\hline Death & $473(19.9 \%)$ & $156(18.0 \%)$ & $317(21.0 \%)$ & $0.83(0.67-1.02)$ & $0.76(0.54-1.08)$ & 0.078 & 0.129 \\
\hline IMV & $509(21.4 \%)$ & $142(16.4 \%)$ & $367(24.3 \%)$ & $0.61(0.49-0.76)$ & $0.71(0.51-1.00)$ & $<0.001$ & 0.053 \\
\hline Admission in ICU* & $753(31.7 \%)$ & $207(23.9 \%)$ & $546(36.3 \%)$ & $0.55(0.46-0.67)$ & $0.58(0.43-0.77)$ & $<0.001$ & $<0.001$ \\
\hline Home discharge & $1197(50.3 \%)$ & $463(53.3 \%)$ & $734(48.5 \%)$ & $1.21(1.03-1.43)$ & $1.14(0.88-1.48)$ & 0.024 & 0.312 \\
\hline
\end{tabular}

${ }^{*}$ Data available for 2372 (women:866; men:1506)

OR=women versus men Odds Ratio

Multi-adjusted model includes adjustment on age, BMI, smoking, microvascular complications, macrovascular complications, hypertension, COPD and treated OSA. Primary composite outcome combines IMV and/or death. IMV: invasive mechanical ventilation; ICU: intensive care unit. 
Table 4 Association of overweight and obesity status with COVID-19-related severe outcomes at day 28 according to sex.

\begin{tabular}{|c|c|c|c|c|c|c|c|c|c|c|c|c|c|c|c|}
\hline & \multicolumn{5}{|c|}{ Primary outcome at D28 } & \multicolumn{5}{|c|}{ Death at D28 } & \multicolumn{5}{|c|}{ IMV at D28 } \\
\hline & \multirow{2}{*}{$\begin{array}{l}\text { Events, } n / \\
\text { participants, } \\
n(\%)\end{array}$} & \multicolumn{2}{|c|}{ Unadjusted } & \multicolumn{2}{|c|}{ Adjusted* } & \multirow{2}{*}{$\begin{array}{l}\text { Events, } n / \\
\text { participants, } \\
n(\%)\end{array}$} & \multicolumn{2}{|c|}{ Unadjusted } & \multicolumn{2}{|c|}{ Adjusted* } & \multirow{2}{*}{$\begin{array}{l}\text { Events, } n / \\
\text { participants, } \\
n(\%)\end{array}$} & \multicolumn{2}{|c|}{ Unadjusted } & \multicolumn{2}{|c|}{ Adjusted* } \\
\hline & & OR $(95 \% \mathrm{CI})$ & $P$-value & OR $(95 \% \mathrm{CI})$ & $P$-value & & OR $(95 \% \mathrm{CI})$ & $P$-value & OR $(95 \% \mathrm{CI})$ & $P$-value & & $\mathrm{OR}(95 \% \mathrm{CI})$ & $P$-value & OR $(95 \% \mathrm{CI})$ & $P$-value \\
\hline \multicolumn{16}{|l|}{$\begin{array}{l}\text { In Men, } n=1512 \\
\text { BMI subgroups }\end{array}$} \\
\hline$<25 \mathrm{~kg} / \mathrm{m}^{2}$ & $\begin{array}{l}141 / 397 \\
(35.5 \%)\end{array}$ & Ref & & Ref & & $\begin{array}{l}98 / 397 \\
(247 \%)\end{array}$ & Ref & & Ref & & $\begin{array}{l}60 / 397 \\
(15.1 \%)\end{array}$ & Ref & & Ref & \\
\hline $25-29.9 \mathrm{~kg} / \mathrm{m}^{2}$ & $\begin{array}{l}234 / 613 \\
(38.2 \%)\end{array}$ & $\begin{array}{l}1.12 \\
(0.86-1.46)\end{array}$ & 0.393 & $\begin{array}{l}1.22 \\
(0.85-1.75)\end{array}$ & 0.291 & $\begin{array}{l}121 / 613 \\
(19.7 \%)\end{array}$ & $\begin{array}{l}0.75 \\
(0.55-1.02)\end{array}$ & 0.063 & $\begin{array}{l}0.89 \\
(0.57-1.40)\end{array}$ & 0.616 & $\begin{array}{l}157 / 613 \\
(25.6 \%)\end{array}$ & $\begin{array}{l}1.93 \\
(1.39-2.69)\end{array}$ & $<0.001$ & $\begin{array}{l}2.23 \\
(1.37-3.63)\end{array}$ & 0.001 \\
\hline$\geq 30 \mathrm{~kg} / \mathrm{m}^{2}$ & $\begin{array}{l}204 / 502 \\
(40.6 \%)\end{array}$ & $\begin{array}{l}1.24 \\
(0.95-1.63)\end{array}$ & 0.117 & $\begin{array}{l}1.25 \\
(0.85-1.84)\end{array}$ & 0.248 & $\begin{array}{l}98 / 502 \\
(19.5 \%)\end{array}$ & $\begin{array}{l}0.74 \\
(0.54-1.02)\end{array}$ & 0.063 & $\begin{array}{l}0.75 \\
(0.45-1.23)\end{array}$ & 0.249 & $\begin{array}{l}150 / 502 \\
(29.9 \%)\end{array}$ & $\begin{array}{l}2.39 \\
(1.71-3.34)\end{array}$ & $<0.001$ & $\begin{array}{l}2.30 \\
(1.39-3.80)\end{array}$ & 0.001 \\
\hline \multicolumn{16}{|l|}{$\begin{array}{l}\text { In Women, } n=868 \\
\text { BMI subgroups }\end{array}$} \\
\hline$<25 \mathrm{~kg} / \mathrm{m}^{2}$ & $\begin{array}{l}49 / 190 \\
(25.8 \%)\end{array}$ & Ref & & & Ref & $\begin{array}{l}37 / 190 \\
(19.5 \%)\end{array}$ & Ref & & Ref & & $\begin{array}{l}19 / 190 \\
(10.0 \%)\end{array}$ & Ref & & Ref & \\
\hline $25-29.9 \mathrm{~kg} / \mathrm{m}^{2}$ & $\begin{array}{l}75 / 251 \\
(29.9 \%)\end{array}$ & $\begin{array}{l}1.23 \\
(0.80-1.87)\end{array}$ & 0.344 & $\begin{array}{l}1.34 \\
(0.75-2.39)\end{array}$ & 0.318 & $\begin{array}{l}48 / 251 \\
(19.1 \%)\end{array}$ & $\begin{array}{l}0.98 \\
(0.61-1.58)\end{array}$ & 0.926 & $\begin{array}{l}1.08 \\
(0.55-2.16)\end{array}$ & 0.816 & $\begin{array}{l}35 / 251 \\
(13.9 \%)\end{array}$ & $\begin{array}{l}1.46 \\
(0.81-2.64)\end{array}$ & 0.213 & $\begin{array}{l}1.61 \\
(0.70-3.70)\end{array}$ & 0.263 \\
\hline$\geq 30 \mathrm{~kg} / \mathrm{m}^{2}$ & $\begin{array}{l}141 / 427 \\
(33.0 \%)\end{array}$ & $\begin{array}{l}1.42 \\
(0.97-2.08)\end{array}$ & 0.073 & $\begin{array}{l}1.31 \\
(0.76-2.28)\end{array}$ & 0.333 & $\begin{array}{l}71 / 427 \\
(16.6 \%)\end{array}$ & $\begin{array}{l}0.82 \\
(0.53-1.28\end{array}$ & 0.391 & $\begin{array}{l}1.05 \\
(0.54-2.04)\end{array}$ & 0.882 & $\begin{array}{l}88 / 427 \\
(20.6 \%)\end{array}$ & $\begin{array}{l}2.34 \\
(1.38-3.96)\end{array}$ & 0.002 & $\begin{array}{l}1.51 \\
(0.70-3.29)\end{array}$ & 0.296 \\
\hline$P$ value* & - & & 0.186 & & 0.546 & - & & 0.594 & & 0.973 & - & & 0.002 & & 0.480 \\
\hline
\end{tabular}

Ref., Reference group.

The primary outcome is defined as invasive mechanical ventilation (IMV) and/or death at D28. Therefore, by design, some patients met the two events, and the sum of both death and IMV is greater than the number of primary outcomes. 
A

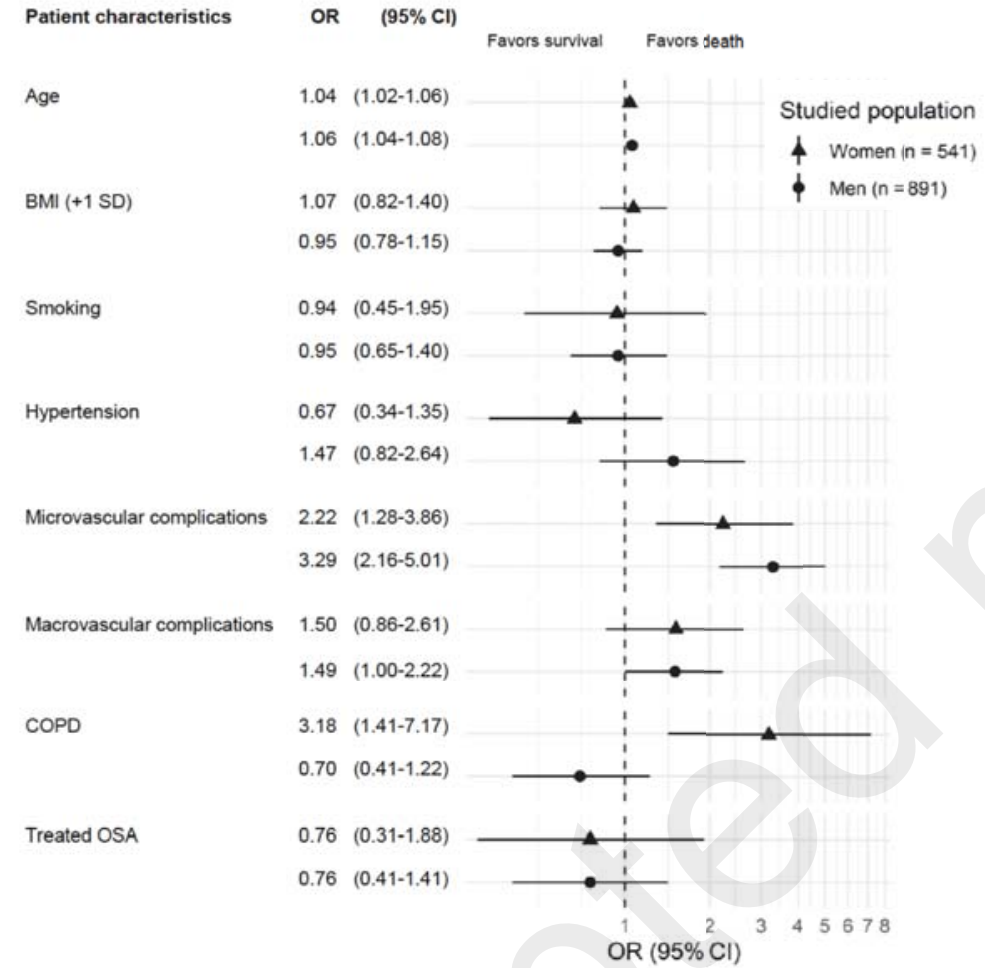

B

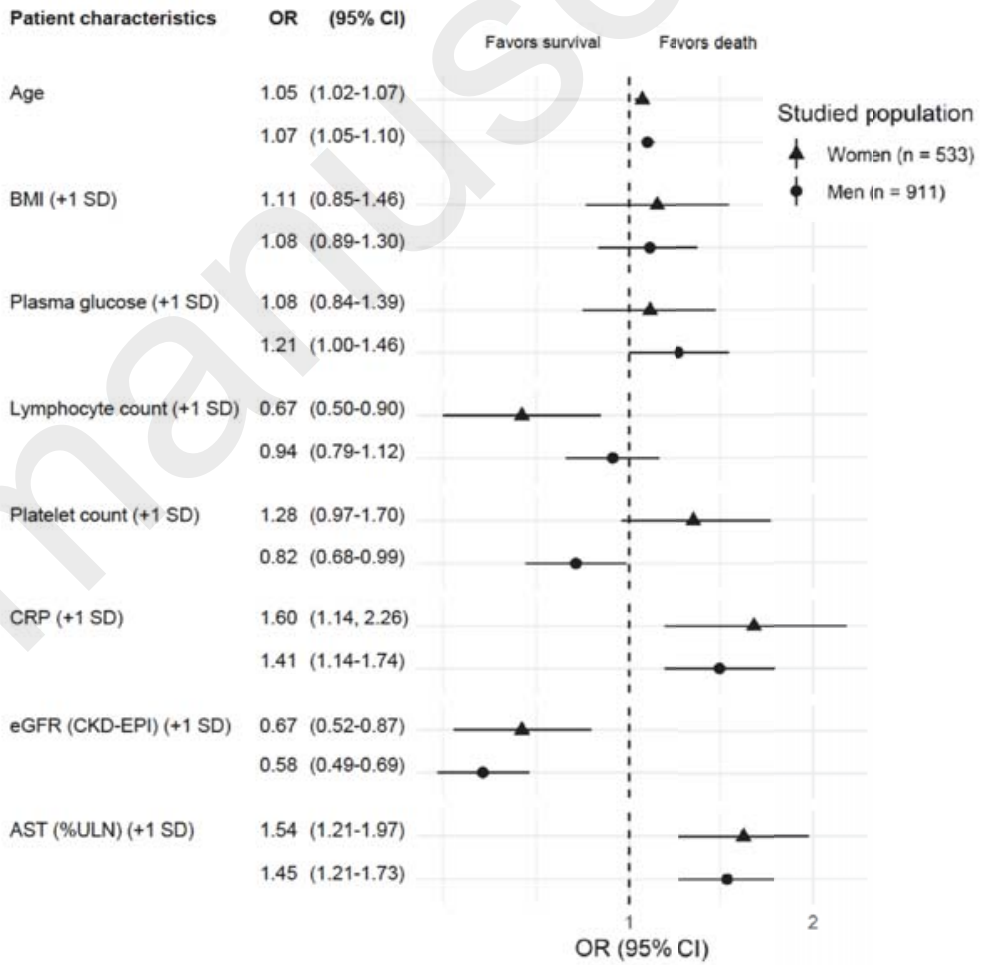




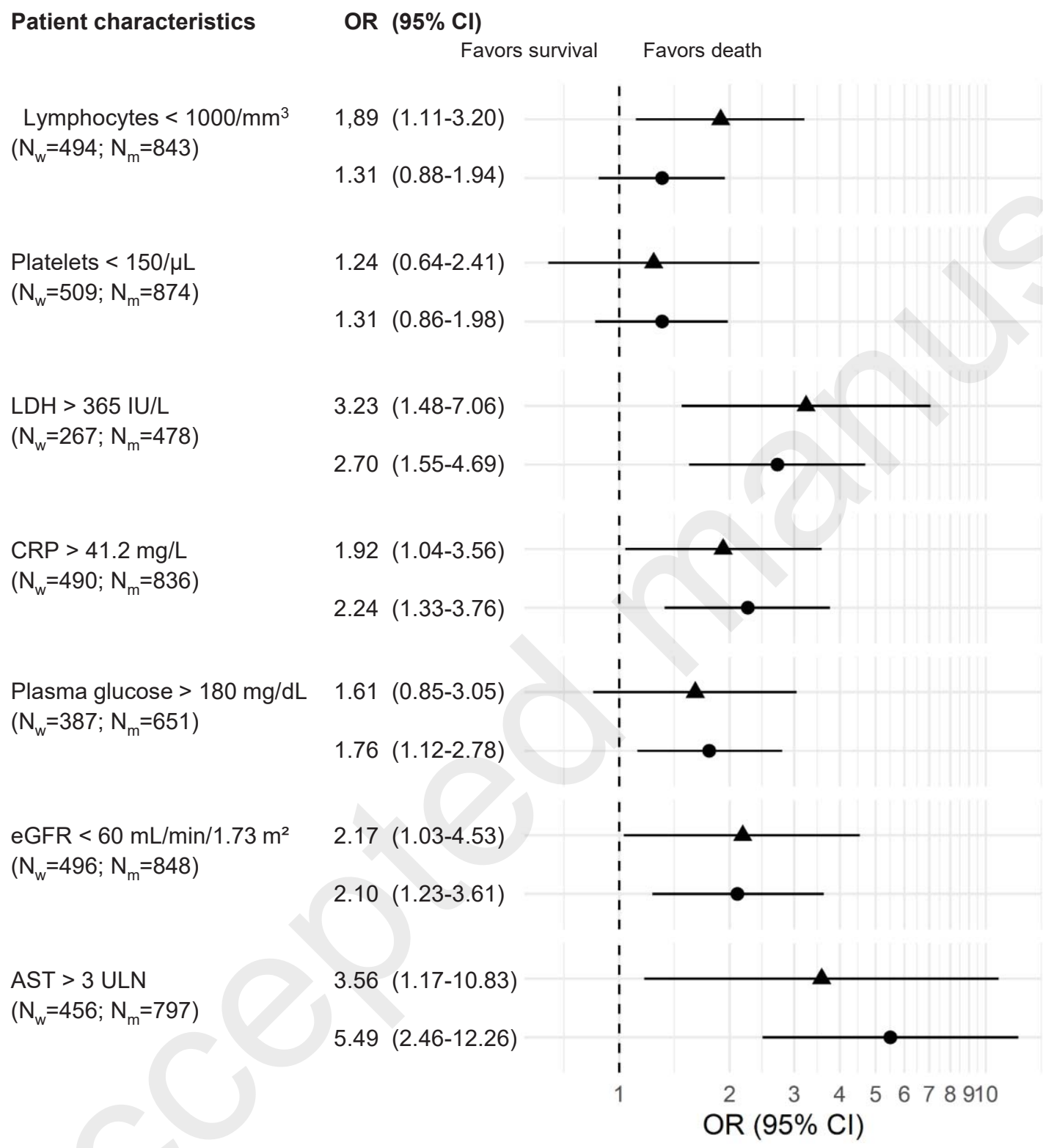

Studied population ㅅ Women \Men 